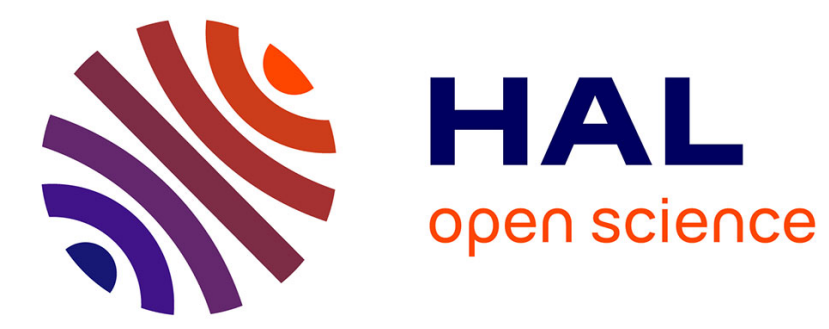

\title{
CHEMICAL AND MAGNETIC ORDERING IN CoPt
}

J. Sanchez, J. Mora -Loṕez, Cédric Leroux, M. Cadeville

\section{To cite this version:}

J. Sanchez, J. Mora-Loṕez, Cédric Leroux, M. Cadeville. CHEMICAL AND MAGNETIC ORDERING IN CoPt. Journal de Physique Colloques, 1988, 49 (C8), pp.C8-107-C8-108. 10.1051/jphyscol:1988840 . jpa-00228587

\section{HAL Id: jpa-00228587 https://hal.science/jpa-00228587}

Submitted on 1 Jan 1988

HAL is a multi-disciplinary open access archive for the deposit and dissemination of scientific research documents, whether they are published or not. The documents may come from teaching and research institutions in France or abroad, or from public or private research centers.
L'archive ouverte pluridisciplinaire HAL, est destinée au dépôt et à la diffusion de documents scientifiques de niveau recherche, publiés ou non, émanant des établissements d'enseignement et de recherche français ou étrangers, des laboratoires publics ou privés. 


\title{
CHEMICAL AND MAGNETIC ORDERING IN CoPt
}

\author{
J. M. Sanchez $\left({ }^{1}\right)$, J. L. Morań-Lopez $\left({ }^{2}\right)$, C. Leroux $\left({ }^{3}\right)$ and M. C. Cadeville $\left({ }^{3}\right)$ \\ (1) Henry Krumb School of Mines, Columbia University, New York, U.S.A. \\ $\left({ }^{2}\right)$ Instituto de Fiśica, U.A.S.L.P., 78000 San Luis Potosi, Mexico \\ ${ }^{3}$ ) I.P.C.M.S., 67070 Strasbourg, Cedex, France
}

\begin{abstract}
Magnetic and chemical ordering in CoPt are ivestigated theoretically and experimentally. Experimental results for the Curie temperature in ordered and disordered states are discussed in the frame of statistical models. The experimental data are well reproduced by including magnetic environmental effects.
\end{abstract}

It is now well established that the Curie temperature of a disordered alloy may differ considerably from that of a partially ordered system [1]. The opposite is also true, magnetism influences chemical ordering and produces substantial changes in the phase diagram [2].

Here we present $a$ detailed investigation of the magnetic and spatial properties of the $\mathrm{Co}_{1-x} \mathrm{Pt}_{x}$ system. Experimental results for the Curie temperature, in both ordered and disordered states, are presented and discussed within the framework of the Ising model solved using the cluster variation method (CVM) [3] in the tetrahedron approximation. In addition, the whole phase diagram, magnetic and chemical is calculated and compared with experimental results $[4,5]$.

The CoPt alloys crystallize with face-centered-cubic structure. At temperatures above $1400 \mathrm{~K}$, the paramagnetic A1 solid solution phase is stable in the whole range of concentrations. At intermediate temperatures $(\approx 1400 \mathrm{~K}$ ) and on the Co rich side, the system orders ferromagnetically but stays atomically disordered. An ordered $\mathrm{Co}_{3} \mathrm{Pt}$ phase has been reported $[4,5]$ to occur with a congruent temperature of approximately $840 \mathrm{~K}$. At $x=0.5$ a CoPt phase $\left(\mathrm{L} 1_{0}\right)$ is observed with a maximum ordering temperature of $1100 \mathrm{~K}$. Furthermore, a $\mathrm{CoPt}_{3}$ phase $\left(\mathrm{L}_{2}\right)$ occurs with a maximum ordering temperature of $1000 \mathrm{~K}$. Both, the $\mathrm{CoPt}$ and the $\mathrm{CoPt}_{3}$ phases are paramagnetic at high temperatures and become ferromagnetic at lower temperatures. The characterization of the ordered state in single phases $\left(A_{1}\right.$, $\left.\mathrm{L}_{2}, \mathrm{~L} 1_{0}\right)$ and two-phase regions $\left(\mathrm{A}_{1}+\mathrm{L} 1_{2}, \mathrm{L1}_{2}+\mathrm{L} 1_{0}\right)$ was made by means of X-ray diffraction, transmission electron microscopy (TEM) and resistivity measurements $[5,6]$. In figure 1 , the full and open circles are respectively the upper and lower temperature transitions.

We studied experimentally the concentration dependence of the Curie temperature $\left(T_{\mathrm{CM}}\right)$ in ordered and disordered phases. Experimental studies on $T_{\mathrm{CM}}$ have been reported previously [7] only for the disordered phases in the Co and Pt rich sides, and for a few ordered systems [8]. Our purpose is to measure and compare $T_{\mathrm{CM}}$ in the two extreme situations; i.e. the most ordered state obtained at low temperatures af-

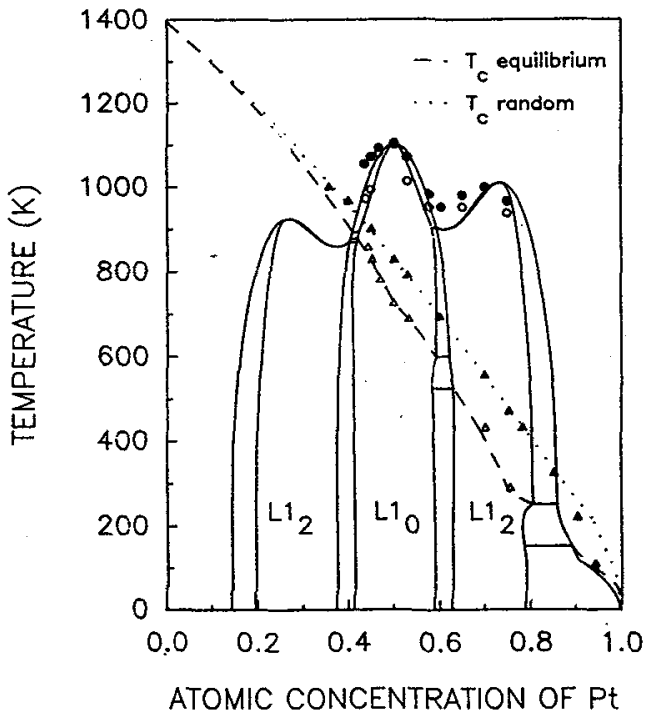

Fig. 1. - The phase diagram of $\mathrm{Co}_{1-x} \mathrm{Pt}_{x}$. The calculated order-disorder phase diagram is shown by the solid lines and the experimental results by the solid and open circles. The calculated $T_{\mathrm{CM}}$ are shown by dotted (random) and broken (equilibrium) lines. The experimental results are shown by the solid and open triangles.

ter a long time anneal, and the most disordered state obtained by rapidly quenching the alloy from the disordered solid solution phase. The optimum values of thermal treatment conditions, were deduced from previous measurements of atomic relaxations and ordering kinetics in these systems [6].

To measure the Curie temperature of metastable disordered states $\left(T_{\mathrm{CM}}^{\mathrm{D}}\right)$, it is necessary that no ordering occurs during the measuring time. On the Co rich side there is no problem since the stable state at $T_{\mathrm{CM}}$ is the disordered $\mathrm{A} 1$ phase. Within the $\mathrm{L} 1_{0}$ stability range, the measurement of $T_{\mathrm{CM}}$ in the disordered state is possible for measurement rates fast enough as compared to the ordering kinetics. Finally, within the $\mathrm{L} 1_{2}$ stability range around $x=0.75$, the $T_{\mathrm{CM}}$ values are low enough to prevent from any change of the atomic 
distribution during the measurement time. Our values for the ordered and disordered phases are plotted in figure 1 .

In order to understand these results and to reproduce the chemical phase diagram, we develop a theoretical model for $\mathrm{Co}_{1-x} \mathrm{Pt}_{x}$ alloys, based on the tetrahedron approximation of the CVM which includes chemical and magnetic interactions. Here, we assume that the internal energy consist of two independent parts; i.e. magnetic and chemical. In general, more elaborate calculations [9] have shown that this approximation is good at high temperatures, therefore our model should be taken as a first approximation.

The chemical energy is written in terms of nearestneighbors (nn) pair interactions $V_{2}$, three-body interactions $V_{3}$ corresponding to triangles of nn atoms, and four-body interactions $V_{4}$ associated to the nn regular tetrahedron of the fcc lattice. The chemical energy is given by:

$$
\begin{aligned}
H_{\text {chem }}=V_{2} \sum_{i j} \sigma_{i} \sigma_{j}+V_{3} \sum_{i j k} \sigma_{i} \sigma_{j} \sigma_{k}+ \\
+V_{4} \sum_{i j k l} \sigma_{i} \sigma_{j} \sigma_{k} \sigma_{i}
\end{aligned}
$$

where the occupation number $\sigma_{i}$ at a lattice site $i$ equals to 1 for Co and - 1 for Pt atoms, and where the sums in equation (1) are carried over all nn-pairs, triangles and tetrahedra in the lattice. The three interaction parameters $V_{2}, V_{3}$ and $V_{4}$ are chosen in order to reproduce the temperatures of the congruent points for $\mathrm{Co}_{3} \mathrm{Pt}$, CoPt and CoPt3. The magnetic energy is expressed in our model in terms of exchange interactions $J_{i j}$ between $n$ sites $i$ and $j$ and is given by:

$$
H_{\mathrm{mag}}=-\sum_{i j} J_{i j} s_{i} s_{j},
$$

where the spin operator $s_{i}$ at site $i$ can take values \pm 1 Experimental observations $[10,11]$ indicate that the magnetic moment of $\mathrm{Co}\left(\mu_{\mathrm{Co}}\right)$ in $\mathrm{Co}_{1-x} \mathrm{Pt}_{x}$ remains essentially constant. That is not the case for the Ptmagnetic moment $\left(\mu_{\mathrm{Pt}}\right)$ which has been found from magnetic measurements [12] to depend on the atomic environment and possibly on the degree of long- and short range order.

In our model, the constant magnetic moment of Co translates into a constant nn exchange interaction between Co atoms and it is determined from the Curie temperature of pure Co. In order to account for chemical environmental effects in $\mu_{\mathrm{Pt}}$, we assume different exchange interactions between $\mathrm{Pt}$ and $\mathrm{Co}$ as well as $\mathrm{Pt}$ atoms in the $\mathrm{Co}_{3} \mathrm{Pt}$, CoPt, $\mathrm{CoPt}_{3}$, and pure $\mathrm{Pt}$ phases. The magnetic moments of $\mathrm{Pt}$ in the Co $\mathrm{C}_{3} \mathrm{Pt}$, CoPt, and $\mathrm{CoPt}_{3}$ are taken, respectively, equal to $0.6 \mu_{\mathrm{Co}}$, $0.45 \mu_{\mathrm{Ce}}$ and $0.3 \mu_{\mathrm{Co}}$. Further details of the model can be found in reference [12].
In figure 1, we compare the calculated equilibrium phase diagram with some of the available experimental data for chemical [5] and magnetic transitions. The broken line and the open triangles are, respectively, the calculated and experimental values for the equilibrium $T_{C M}$ in the ordered phases. Furthermore, we show the experimental values of $T_{\mathrm{CM}}$ for disordered alloys quenched from high temperatures and data from reference [7]. We mimic the experimental situation by calculating the $T_{\mathrm{CM}}$ of an alloy without chemical shortrange order (random) but which is allowed to achieve magnetic equilibrium; the dotted line show the calculated results.

We find a very good agreement between the calculated and the experimental results in the whole phase diagram. In particular the agreement between the experimental and calculated Curie temperatures of the random alloys is excellent. This is a strong indication that our model provides a correct description of environmental effects (short- and long-range order) on the magnetic moments of Pt.

\section{Acknowledgment}

This paper was supported in part by the NSF through Grants No. D'MR-8510594 and INT8409776, by CoNaCyT (Mexico) through Grant No. 140106G202-187 and by SEP (Mexico) C87-08-0300.

[1] Cadeville, M. C. and Moran-Lopez, J. L., Phys. Rep. 153 (1987) 331.

[2] Dahmani, C. E., Cadeville, M. C., Sanchez, J. M. and Moran-Lopez, J. L., Phys. Rev. Lett. $\mathbf{5 5}$ (1985) 1208.

[3] Kikuchi, R., Phys. Rev. 81 (1951) 988.

[4] Dahmani, C. E., Doctoral Dissertation, Univ. Louis Pasteur, Strasbourg, France (1985) unpublished.

[5] Leroux, C., Cadeville, M. C., Dahmani, C. E., Inden, G., Gahn, F. and Hintz, F. (preprint).

[6] Leroux, C., Doctoral Dissertation, Univ. Louis Pasteur, Strasbourg, France (1988) unpublished.

[7] Crangle, J. and Pearson, D., Proc. Roy. Soc. A 255 (1960) 509; Crangle, J. and Scott, W. R., J. Appl. Phys. 36 (1965) 921.

[8] Cadeville, M. C., Dahmani, C. E. and Kern, F., J. Magn. Magn. Mater. 54-57 (1986) 1055.

[9] Bibier, A. and Gautier, F., J. Magn. Magn. Mater. 54-57 (1986) 967.

[10] Van Laar, B., J. Phys. France 25 (1964) 600.

[11] Tessier, B., Doctoral Dissertation, USMG Grenoble, France (1977) unpublished.

[12] Sanchez, J. M., Moran-Lopez, J. L., Leroux, C. and Cadeville, M. C., J. Phys. C 21 (1988) L1091-1096. 